\title{
Conceptos básicos de genética y herencia mendeliana
}

\section{Basics of genetics and mendelian inheritance}

\section{Diana V. Sánchez-Martínez ${ }^{a}$, Dafne J. Juárez-Sandoval ${ }^{b}$}

\begin{abstract}
:
Genetics is the branch of biology whose area of study is the transmission of hereditary characters through genes and DNA from parents to their children through reproduction, which are translated into physical characteristics such as; eye color, hair texture, etc., and diseases.

The conceptual map presents the basic concepts of genetics to understand the processes of inheritance, as well as the scientist considered the father of this area for establishing the laws of these mechanisms in peas through crosses in homozygous and heterozygous organisms.
\end{abstract}

\section{Keywords:}

DNA, genetic diseases, Genetics, heterozygous, homozygous.

\section{Resumen:}

La genética es la rama de biología cuya área de estudio es la transmisión de caracteres hereditarios a través de los genes y el ADN de los progenitores a sus hijos a través de la reproducción, las cuales se traducen en características físicas como; el color de ojos, textura de cabello, etc., y enfermedades genéticas.

En el mapa conceptual se presentan los conceptos básicos de la genética para comprender los procesos de la herencia, así como el científico considerado el padre de dicha área por establecer las leyes de dichos mecanismos en los guisantes a través de cruzas en organismos homocigotos y heterocigotos.

\section{Palabras Clave:}

$A D N$, enfermedades genéticas, Genética, heterocigotos, homocigotos.

\section{Síntesis}

La genética es la ciencia que estudia la herencia biológica, es decir transmisión de los caracteres morfológicos y fisiológicos que pasan de un ser vivo a sus desdendientes. El material genético es el ácido desoxirribonucleico (ADN) el cual se encuentra en el interior de las células y se transmite de una generación a otra, este se organiza a partir de pequeñas subunidades llamadas gen, que contienen información específica para un carácter.

Los caracteres son cada una de las particularidades morfológicas y fisiológicas de un ser vivo, por ejemplo ojos azules, pelo rizado, altura, entre otros.

Los alelos son formas alternativa de un gen y cuando estos son semejantes entre los progenitores darán como 41 resultado un organismo homicigoto y si por el contrario estos son distintos entonces el resultado sería un descendiente heterocigoto. La constitución genética de las especies forma parte de su genotipo y la forma en como esta se manifiesta físicamente sería el fenotipo.

Gregor Mendel es conocido como el padre de la genética, ya que debido a sus experimentos con guisantes, desarrollo las tres leyes de la herencia.

La 1era. Ley de Mendel refiere a la uniformidad, la cual establece que al cruzar dos individuos de razas puras toda su descendencia en la primera generación será fenotípicamente igual. Por otro lado la 2da. Ley de Mendel indica que el gen recesivo se va a expresar en la segunda generación en una proporción 3:1. Finalmente la 3era. Ley establece que hay razgos heredados que se obtienen de

a Autor de Correspondencia, Universidad Autónoma del Estado de Hidalgo, https://orcid.org/0000-0002-7660-7234, Email:

diana_sanchez8479@uaeh.edu.mx

b Universidad Autónoma del Estado de Hidalgo, https://orcid.org/0000-0002-9082-6628, Email: ju423514@uaeh.edu.mx 
manera independiente sin seguir un patrón establecido y no afecta la transmisión de otros razgos.

Algunas de las enfermedades frecuentes en la transmisión hereditaria son el albinismo, en la cual no se produce melanina. La hemofilia que representa un transtorno en la que la sangre no coagula ante heridas y el daltonismo que afecta a distinguir ciertos colores con la vista.

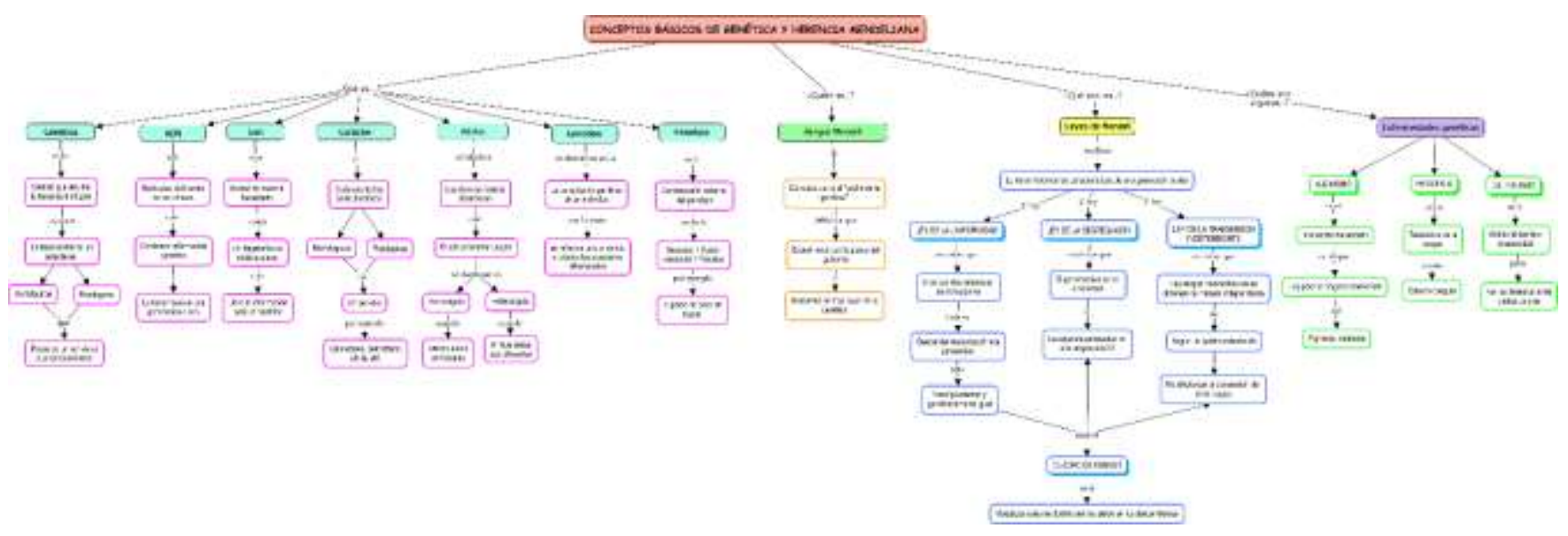

\section{Referencias}

[1] ACC. (2019). Las leyes de Mendel, cuadro de Punnet paso a paso, explicación. Consultado el 13 de septiembre de 2021. Disponible en: https://www.youtube.com/watch?v=LXXK211pdv8

[2] Xunta de Galicia. (2021). Genética Mendeliana. Consultado el 13 de septiembre de 2021. Disponible en: https://www.edu.xunta.gal/centros/iesriocabe/system/files/u1/T_206_G en_tica_Mendeliana.pdf

[3] Instituto de Bernabeu. (2021). ¿Qué es la genética? Consultado el 13 de septiembre de 2021. Disponible en: https://www.ibbiotech.com/es/info/que-es-la-genetica/ 